\title{
Validity of the Korean Version of DIVA-5: A Semi-Structured Diagnostic Interview for Adult ADHD
}

This article was published in the following Dove Press journal: Neuropsychiatric Disease and Treatment

\author{
Minha Hong (D) ${ }^{\prime}$ \\ JJ Sandra Kooij ${ }^{2,3}$ \\ Bongseog Kim (iD ${ }^{4}$ \\ Yoo-Sook Joung ${ }^{5}$ \\ Hanik K Yoo (iD ${ }^{6}$ \\ Eui-Jung $\mathrm{Kim} \mathbb{D}^{7}$ \\ Soyoung Irene $\mathrm{Lee}^{8}$ \\ Soo-Young Bhang 9 \\ Seung Yup Lee $\mathbb{D}^{10}$ \\ Doug Hyun Han (D) 1 \\ Young Sik Lee (ID ${ }^{11}$ \\ Geon Ho Bahn (1D) ${ }^{10}$
}

'Department of Psychiatry, Myongii Hospital, Hanyang University College of Medicine,

Goyang, Korea; ${ }^{2}$ PsyQ, Psycho-Medical Programs, Expertise Center Adult ADHD,

The Hague, The Netherlands; ${ }^{3}$ Department of Psychiatry, Amsterdam University Medical Center, Amsterdam, The Netherlands;

${ }^{4}$ Department of Psychiatry, Inje University

College of Medicine, Seoul, Korea;

${ }^{5}$ Department of Psychiatry, Samsung Medical Center, Sungkyunkwan University School of Medicine, Seoul, Korea; ${ }^{6}$ Department of Clinical Psychiatry, Seoul Brain Research Institute, Seoul, Korea; ${ }^{7}$ Department of Psychiatry, College of Medicine, Ewha Womans University, Seoul, Korea; ${ }^{8}$ Department of Psychiatry, Soonchunhyang University College of Medicine, Bucheon, Korea; ${ }^{9}$ Department of Psychiatry, Nowon Eulji University Hospital, Eulji University School of Medicine, Seoul, Korea; ${ }^{0}$ Department of Psychiatry, Kyung Hee University School of Medicine, Seoul, Korea;

"Department of Psychiatry, Chung-Ang University College of Medicine, Seoul, Korea

Correspondence: Geon Ho Bahn Department of Psychiatry, Kyung Hee University School of Medicine, 23 Kyungheedae-Ro, Dongdaemungu, Seoul 02447, Korea

Tel +82-2-958-8556

Fax+82-2-957-1997

Email mompeian@khu.ac.kr
Background: This study was to assess the validity of the Korean version of the semistructured Diagnostic Interview for Adult ADHD, third edition (DIVA-5). The secondary aim was to compare sociodemographic and psychiatric comorbidities in adult patients with and without a diagnosis of ADHD.

Methods: A total of 279 participants were recruited from nine psychiatric outpatient clinics in Korea. All participants were administered the Mini-International Neuropsychiatric Interview (MINI) Plus v.5.0.0, the Adult ADHD Self-Report Scale v1.1 (ASRS-v1.1) Symptom Checklist, and DIVA-5. Diagnosis concordance between two board-certified psychiatrists and DIVA-5 were analysed.

Results: The DIVA-5 showed a diagnostic accuracy of $92 \%$, a sensitivity of $91.30 \%$, and a specificity of $93.62 \%$. Significant clinical and demographic differences between ADHD and control groups were found.

Conclusion: The Korean version of DIVA-5 is a reliable tool for assessing and diagnosing ADHD in adult Korean populations.

Keywords: adult ADHD, validity, DIVA-5, Korean

\section{Introduction}

Attention deficit/hyperactivity disorder (ADHD), which was formerly classified under the "disorders usually first diagnosed in infancy, childhood, or adolescence" section, was introduced as one of the neurodevelopmental disorders in the Diagnostic and Statistical Manual of Mental Disorders, fifth edition (DSM-5). ${ }^{1}$ ADHD prevalence in adulthood is estimated to be between five and eight percent, ${ }^{2}$ and the persistence of ADHD in children into adulthood varies between $60 \%$ and $80 \% .^{3,4}$ Numerous negative outcomes, such as criminality, academic failure, unemployment, behavioural disturbance, addiction, accidents, and premature death, have been reported to be related to ADHD. ${ }^{5,6}$

Although early diagnosis and early intervention is needed in adults, as well as in children and adolescents, there is no single gold standard tool for the diagnosis of ADHD. A detailed interview by experienced clinicians, and information gathered from informant(s) in addition to the patient are highlighted when diagnosing ADHD. $^{7}$

To our knowledge, there are only two semi-structured interviews available for the accurate diagnostic assessment of ADHD, based on the DSM criteria in the 
adult population: Conners' Adult ADHD Diagnostic Interview for DSM-IV (CAADID), ${ }^{8}$ and the Diagnostic Interview for ADHD in Adults (DIVA-2). ${ }^{9}$ However, no official and commercial version of the CAADID is available in the Korean language. The DIVA-2 is a semistructured diagnostic interview that is available on the DIVA Foundation website. ${ }^{10}$ The DIVA has recently been updated according to the DSM-5 criteria, and DIVA-5 is currently available in 12 translated versions, with many more to come. In 2016, the DIVA-2 was revised into DIVA-5 based on DSM-5 criteria by Dr P Asherson of the London institute of Psychiatry (London, UK), Dr A Ramos-Quiroga of the University of Barcelona (Barcelona, Spain), and S Kooij and A Bron of the DIVA Foundation. The DSM-5 criteria for ADHD, issued with the permission of the American Psychiatric Association, was adopted. The previous version, DIVA-2, has been validated in Swedish and Spanish, but none of the DIVA5 versions have been validated yet.

The primary aim of the present study was to examine the criterion validity of the Korean version of the DIVA-5 in an adult clinical sample. The secondary aim was to compare sociodemographic and psychiatric comorbidities in adult patients with and without a diagnosis of ADHD.

\section{Methods}

\section{Procedures and Participants}

Translation of the Diagnostic Interview for ADHD in Adults (DIVA-5) into Korean

The translation of the Dutch version of the DIVA-5 into Korean, as well as its back translation, were carried out according to the standards designed and approved by the DIVA Foundation (The Hague, The Netherlands). The Dutch version was translated into Korean by a professional translator and, where necessary, adjusted to the language and wording used in clinical psychiatry in Korea by clinicians experienced in adult ADHD (DY). The back translation from Korean to Dutch was done by the World Translation Institute (www.worlsys.biz). Expenses were paid by the Adult ADHD Study Group of the Korean Academy of Child and Adolescent Psychiatry. All of these processes were supervised by Professor GHB (Kyung Hee University, Seoul), BSK (Inje University, Seoul), SYB (Eulji University, Seoul), ISL (Soonchunhyang University, Buchun), SWC (Kyung Hee University), MH (Myongji Hospital, Seoul), RH (Kyung Hee University), and JWH (Kangwon National Univerity, Chuncheon, Korea). The adaptation of the Korean version was based on the advice provided by S Kooij and A Bron of the DIVA Foundation; this collaboration ended in January, 2017.

All study participants were recruited from the Outpatient Services of eight university hospitals (Kyung Hee University Hospital, Samsung Seoul Hospital, Inje University Sanggye Paik Hospital, Chung Ang University Hospital, Nowon Eulji Hospital, Ewha Womans University Hospital, Myongji Hospital, and Soonchunhyang Bucheon Hospital) between January 2017 and December 2018. Those who agreed to participate provided written informed consent. The inclusion criteria was a referral for an ADHD assessment, and being between the ages of 17 and 65 years. Exclusion criteria included: treatment with ADHD medication in the previous 3 months; the presence of congenital genetic diseases; organic brain disease; severe physical disease requiring management such as renal failure, liver disease, cancer; a history of schizophrenia, bipolar I disorder, and other psychotic disorders within six months; and autism spectrum disorder; intellectual disability.

The clinical psychiatric assessment was performed by two board-certified psychiatrists. If the diagnosis of ADHD by the two experienced psychiatrists was consistent, patients were classified in the ADHD group; if not, they were classified as controls. All participants in this study were assessed using the Mini-International Neuropsychiatric Interview (MINI) Plus version 5.0.0 (MINI-Plus V.5.0.0) to evaluate comorbidity and were administered the Adult ADHD Self-Report Scale Symptoms Checklist version 1.1 (ASRS-V1.1). Participants were also asked to fill out a questionnaire designed to collect sociodemographic characteristics. Trained psychiatrists or psychologists then tested all participants using DIVA-5 to confirm an adult ADHD diagnosis according to DSM-5 criteria.

\section{Assessment Tools \\ Diagnostic Interview for ADHD in Adults (DIVA-5), Korean Version}

DIVA is a semi-structured interview tool administered by a clinician. DIVA-2, which was based on DSM-IV criteria for ADHD in adults, ${ }^{9}$ was revised into DIVA $5.0^{11}$ based on the DSM-5 criteria. DIVA-5 was translated into Korean according to the process described above. DIVA-5 consists of three parts that cover the following areas: 1) ADHD symptoms in childhood and adulthood, 2) age of ADHD onset, and 3) areas of impairment due to ADHD. If three or more criteria were met for either inattention and/or hyperactivity/impulsivity in childhood before the age of 12 years old, and five or more criteria were met in adulthood as reported by the patient and collateral informant(s), 
the requirements for a clinical diagnosis of lifetime ADHD were considered to have been met.

\section{Adult ADHD Self-Report Scale (ASRS)}

The ASRS is an 18-item self-report scale based on the DSMIV symptom criteria developed by the Korean Workgroup on Adult ADHD in conjunction with the World Health Organization. $^{12}$ The scale is composed of two parts, parts $\mathrm{A}$ and $\mathrm{B}$. The scale focuses on symptom frequency rather than severity to make scale instructions easier for participants to understand. Each ASRS question asks respondents how often a particular ADHD symptom had occurred over the past six months using a 5-point Likert scale ranging from 0 (never) to 4 (very often). Total scores ranged from 0 to 72 . The Korean version of the ASRS has been validated. ${ }^{13}$ Part $\mathrm{A}$ is called the ASRS Screener, which is the short form of the ASRS, and comprises six questions selected based on stepwise-logistic regression. ${ }^{12}$ The ASRS Screener score is the sum of the dichotomous responses for the six questions - the scoring approach recommended by the ASRS V1.1 Screener manual - whereby respondents who endorsed at least four out of six items were considered at "elevated" risk for ADHD. ${ }^{14}$

\section{MINI-PLUS V.5.0 Structured Interview}

The MINI $^{15}$ is a short, structured diagnostic interview developed jointly by psychiatrists and clinicians in the United States and Europe for DSM-IV-TR ${ }^{16}$ and ICD$10 .^{17}$ It is applied to assess current DSM-IV Axis I psychiatric morbidities.

\section{Statistical Analysis}

All computations were performed using SPSS software V.21.0 (IBM Corp, Armonk, NY, USA). Group comparisons were performed using the Pearson's $\chi^{2}$ test for categorical variables, and mean differences in continuous variables were evaluated using the independent samples $t$-test. A $\mathrm{p}<0.05$ was used to define statistical significance. The clinical ADHD diagnosis established by two clinical experts was used as the external criterion for the calculation of sensitivity, specificity, positive predictive value (PPV), negative predictive value (NPV), and area under the receiver operating characteristic curve (AUC) of DIVA-5.

\section{Research Ethics}

This study's protocol was approved by the Institutional Review Board of the institutes from which participants were recruited, including Kyung Hee University Hospital (KMCIRB 2017-02-054), Sanggye Paik Hospital
(SGPAIK-2017-05-012-005), Ewha Womans University Hospital (EUMC 2017-01-013), Chung Ang University Hospital (IRB-No. 1741-005-279), Soonchunhyang University Hospital (SCHBC 2016-11-012-006), Eulji University Hospital (EMCS 2016-07-001), Sungkyunkwan University Samsung Medical Center (SMC 2016-07-061) and Myongji Hospital (MJH 2017-07-013-001); the principal investigator was GHB. Written informed consent was provided by all participants. Some of the data relating to participants in this study were published in a previous paper. ${ }^{18}$ The study has been performed in accordance with the ethical standards laid down in the Helsinki II Declaration about informed consent, voluntariness and anonymity.

\section{Results}

The demographic characteristics of the ADHD and control groups are given in Table 1. There were significant differences between the two groups in terms of educational level and employment status $\left(\chi^{2}=24.962, p=0.000 ; \chi^{2}=\right.$ 48.796, $p<0.001$ ).

The presence of comorbid psychiatric disorders was assessed using MINI-PLUS 5.0 (Table 1). The proportion of participants with a comorbid disorder was higher in the ADHD group (72.4\%) than in the control group (14.0\%).

The validity of the DIVA- 5 was assessed by comparing the scores of the participants, with and without a diagnosis of ADHD, by two independent clinicians. Table 2 presents the sensitivity and specificity of DIVA-5 and ASRS (both Screener and Total scores). In the clinical utility study of the Korean ASRS, a cut-off score of 32 was suggested. ${ }^{19}$ DIVA-5 had a sensitivity and specificity of $91.30 \%$ and $93.62 \%$, respectively.

\section{Discussion}

This is the first study to validate the DIVA-5. The results of this study demonstrate DIVA-5 to be a reliable diagnostic tool with good predictive value for the diagnosis of ADHD in adults in a Korean psychiatric population. Given that only two other studies have investigated the validity of the previous version of the DIVA (DIVA-2), ${ }^{20,21}$ to our knowledge this is the first study with the appropriate statistical analysis to explore the psychometric properties of the revised version of DIVA-5 in Korean. The validation of this diagnostic interview provides clinicians with a useful diagnostic tool for assessing ADHD in adult Korean populations.

One of the advantages of DIVA-5 is that it comprehensively assesses symptoms of ADHD, from childhood to 
Table I Demographic Characteristics of the Participants $(N=279)$

\begin{tabular}{|c|c|c|c|c|}
\hline & $\begin{array}{l}\text { Persons with ADHD } \\
(\mathrm{n}=138)\end{array}$ & $\begin{array}{l}\text { Controls } \\
(n=14 I)\end{array}$ & & $p$ value \\
\hline & $n(\%)$ & $n(\%)$ & & \\
\hline $\begin{array}{l}\text { Age, years, mean } \pm S D \\
\text { Male } \\
\text { Female }\end{array}$ & $\begin{array}{l}27.0 \pm 9.0 \\
94(68.1) \\
44(31.9)\end{array}$ & $\begin{array}{l}27.5 \pm 6.9 \\
80(56.7) \\
61(43.3)\end{array}$ & $\begin{array}{l}\mathrm{t}=-0.564 \\
\chi^{2}=3.847\end{array}$ & $\begin{array}{l}0.573 \\
0.050\end{array}$ \\
\hline $\begin{array}{l}\text { Education } \\
\text { Middle school or less } \\
\text { High school } \\
\text { College or university } \\
\text { Graduate school }\end{array}$ & $\begin{array}{l}5(3.6) \\
85(61.6) \\
36(26.1) \\
12(8.7)\end{array}$ & $\begin{array}{l}0(0.0) \\
53(37.6) \\
72(51.1) \\
16(11.3)\end{array}$ & $\begin{array}{l}\chi^{2}=24.962 \\
- \\
- \\
- \\
-\end{array}$ & $\begin{array}{l}<0.001 \\
- \\
- \\
- \\
-\end{array}$ \\
\hline $\mathrm{IQ}$, mean $\pm \mathrm{SD}$ & $99.65( \pm 17.10)$ & $113.48( \pm 13.12)$ & $t=-7.15$ & $<0.001$ \\
\hline $\begin{array}{l}\text { ASRS, mean } \pm \text { SD } \\
\text { ASRS Screener } \\
\text { ASRS Total score }\end{array}$ & $\begin{array}{l}3.74 \pm 1.88 \\
29.90 \pm 16.63\end{array}$ & $\begin{array}{l}1.27 \pm 1.52 \\
12.52 \pm 9.22\end{array}$ & $\begin{array}{l}t=12.06 \\
t=10.77\end{array}$ & $\begin{array}{l}<0.001 \\
<0.001\end{array}$ \\
\hline $\begin{array}{l}\text { Employment } \\
\text { Job } \\
\text { No job } \\
\text { Student }\end{array}$ & $\begin{array}{l}57(51.3) \\
40(29.0) \\
4 I(29.7)\end{array}$ & $\begin{array}{l}59(41.8) \\
11(7.8) \\
71(50.4)\end{array}$ & $\begin{array}{l}48.796 \\
- \\
-\end{array}$ & $\begin{array}{l}<0.001 \\
- \\
-\end{array}$ \\
\hline $\begin{array}{l}\text { Comorbid disorders } \\
\text { Mood disorder } \\
\text { Anxiety disorder } \\
\text { SUD } \\
\text { Others* }\end{array}$ & $\begin{array}{l}41(29.7) \\
20(14.5) \\
14(10.1) \\
25(18.1)\end{array}$ & $\begin{array}{l}10(7.0 .) \\
8(5.6) \\
0(0.0) \\
2(1.4)\end{array}$ & $\begin{array}{l}- \\
- \\
- \\
-\end{array}$ & $\begin{array}{l}- \\
- \\
- \\
-\end{array}$ \\
\hline
\end{tabular}

Note: *Others: suicide ideation, trauma- and stress-related disorder, motor disorder, personality disorder, obsessive-compulsive and related disorder, and eating disorder.

Abbreviations: ADHD, attention deficit/hyperactivity disorder; SD, standard deviation; IQ, intelligent quotient; ASRS, Adult ADHD Self-Report Scale; SUD, substance use disorder.

Table 2 Sensitivity and Specificity of the DIVA-5 and the ASRS Screener

\begin{tabular}{|l|l|l|l|}
\hline & $\begin{array}{l}\text { ASRS Screener } \\
\text { (Cut-Off = 4) }\end{array}$ & $\begin{array}{l}\text { ASRS Total } \\
\text { (Cut-Off = 32) }\end{array}$ & DIVA \\
\hline Sensitivity & 63.77 & 64.15 & 91.30 \\
Specificity & 90.07 & 92.54 & 93.62 \\
False-positives & 9.93 & 7.46 & 6.38 \\
False-negatives & 36.23 & 35.84 & 8.70 \\
PPV & 86.27 & 96.45 & 93.33 \\
NPV & 71.75 & 44.92 & 91.67 \\
Accuracy & 0.77 & 0.70 & 0.92 \\
AUC & 0.769 & 0.707 & 0.925 \\
\hline
\end{tabular}

Abbreviations: DIVA-5, Diagnostic Interview for ADHD in Adults-5; ASRS, Adult ADHD Self-Report Scale; PPV, positive predictive value; NPV, negative predictive value; AUC, area under the curve.

adulthood, by using behavioural examples for each DSM-5 criterion. Moreover, the extensive assessment of lifetime impairment in five areas of psychological functioning is another advantage of the DIVA 5.0 in comparison with other tools. As it is a semi-structured interview for the clinician, it does not have the weaknesses of self-report measures.

Although Kessler et $\mathrm{al}^{22}$ found that the 6-item ASRS Screener, which is based on dichotomized scoring, showed 
the best sensitivity and specificity for diagnosing ADHD adults, the Korean version of the full ASRS outperformed the ASRS Screener. ${ }^{19}$ Our study results were in line with Heo et al. ${ }^{19}$ Considering the relatively lower sensitivity the ASRS both Screener and Total compared to the DIVA-5, the ASRS should be used with caution.

We found a higher proportion of unemployment in participants with ADHD compared to controls. This is consistent with the literature. ${ }^{23,24}$ In those who had work, the proportion of simple laborers and skilled workers in participants with ADHD was higher than that of managers and experts compared to controls (data not shown). This is compatible with the fact that ADHD is associated with underachievement, first at school and later at work. ${ }^{25,26,27}$

Regarding comorbid psychiatric disorders, we found a large difference between the ADHD and control groups. The high comorbidity rate in the ADHD group (72\%) is comparable to previously reported results. ${ }^{4}$ In our study, only $2.1 \%(3 / 141)$ of controls had psychiatric disorders. We assumed that this was because the major participating institutions were university hospitals and, as university students were more likely to participate in the study as controls, the proportion of "very healthy" participants was higher. This needs to be further verified in a well-designed study, such as a cohort study.

This study had some limitations. First, as most of the subjects - patients and healthy controls-were recruited from metropolitan areas, the study cannot be said to be representative of the general Korean population. Second, male overrepresentation can be partially explained as reflection in the sample recruitment that the prevalence of clinical diagnosis in Korea is almost twice higher in males than females. ${ }^{28}$

Third, the criterion validity of DIVA-5 in this study only refers to adult symptoms, since ASRS include only symptoms of ADHD in adulthood and no instruments have been included for childhood symptoms. In addition, because there were no valid interview tools specific to adults with ADHD in Korean, DIVA-5 was compared to only a rating scale such as ASRS. Despite these limitations, we found sound sensitivity and specificity values for DIVA-5 and expect the interview to be extensively used in clinical practice and research settings. This may increase the awareness surrounding, and diagnostic assessment of, adult ADHD in the Korean population.

\section{Acknowledgments}

The authors thank all research assistants from each institute, patients, and healthy controls who participated in this study. The theme of this article was presented at the Spring meeting of the Korean Academy of Child and Adolescent Psychiatry, May 10, 2019, Seoul, Korea.

\section{Funding}

This research received no specific grant from any funding agency, commercial or not-for-profit sectors.

\section{Disclosure}

The authors have no potential conflicts of interest to disclose for this work.

\section{References}

1. American Psychiatric Association. Diagnostic and Statistical Manual of Mental Disorders, 5th ed. Washington, D.C.: American Psychiatric Association; 2013.

2. Polanczyk G, de Lima MS, Horta BL, Biederman J, Rohde LA. The worldwide prevalence of ADHD: a systematic review and metaregression analysis. Am $J$ Psychiatry. 2007;164(6):942-948. doi:10.1176/ajp.2007.164.6.942

3. Kooij SJ, Bejerot S, Blackwell A, et al. European consensus statement on diagnosis and treatment of adult ADHD: the European network adult ADHD. BMC Psychiatry. 2010;10:67.

4. Fayyad J, Sampson NA, Hwang I, et al. The descriptive epidemiology of DSM-IV adult ADHD in the World Health Organization world mental health surveys. Atten Defic Hyperact Disord. 2017;9 (1):47-65. doi:10.1007/s12402-016-0208-3

5. Dalsgaard S, Ostergaard SD, Leckman JF, Mortensen PB, Pedersen MG. Mortality in children, adolescents, and adults with attention deficit hyperactivity disorder: a nationwide cohort study. Lancet. 2015;385(9983):2190-2196. doi:10.1016/S0140-6736(14) 61684-6

6. Biederman J, Faraone SV, Spencer TJ, Mick E, Monuteaux MC, Aleardi M. Functional impairments in adults with self-reports of diagnosed ADHD: a controlled study of 1001 adults in the community. J Clin Psychiatry. 2006;67(4):524-540. doi:10.4088/ JCP.v67n0403

7. Seixas M, Weiss M, Muller U. Systematic review of national and international guidelines on attention-deficit hyperactivity disorder. J Psychopharmacol. 2012;26(6):753-765. doi:10.1177/ 0269881111412095

8. Epstein J, Johnson D. Conners' Adult ADHD Diagnostic Interview for DSM-IV. North Tonawanda: Multi-Health Systems; 2001.

9. Kooij J, Francken M. DIVA 2.0. Diagnostic interview voor ADHD in adults bij volwassenen [DIVA 20 diagnostic interview ADHD in adults]. DIVA Foundation; 2010. Available from: http://www.divacen ter.eu/DIVA.aspx.

10. Kooij JS. Adult ADHD: Diagnostic Assessment and Treatment. Springer Science \& Business Media; 2012.

11. Kooij J, Francken M, Bron T. DIVA-5. 2010.

12. Kessler RC, Adler L, Ames M, et al. The World Health Organization adult ADHD self-report scale (ASRS): a short screening scale for use in the general population. Psychol Med. 2005;35(2):245-256. doi:10.1017/S0033291704002892 
13. Kim JH, Lee EH, Joung YS. The WHO adult ADHD self-report scale: reliability and validity of the Korean version. Psychiatry Investig. 2013;10(1):41-46. doi:10.4306/pi.2013.10.1.41

14. Adler L, Kessler R, Spencer T. Adult Self Report Scale, ASRS-V1. 1 Screener. New York: World Health Organization; 2003.

15. Sheehan DV, Lecrubier Y, Sheehan KH, et al. The Mini-International Neuropsychiatric Interview (M.I.N.I.): the development and validation of a structured diagnostic psychiatric interview for DSM-IV and ICD-10. J Clin Psychiatry. 1998;59 Suppl 20:22-33;quiz 34-57

16. American Psychiatric Association. Diagnostic and Statistical Manual of Mental Disorders, 4th Ed. Washington, D.C.: American Psychiatric Association; 2000.

17. World Health Organization. The ICD-10 classification of mental and behavioral disorders. Geneva:World Health Organization; 1992

18. Hong M, Lee YS, Kim B, et al. Clinical utility and cut-off scores of the Korean adult attention-deficit/hyperactivity disorder rating scale. J Korean Acad Child Adolesc Psychiatry. 2019;30(3):116-120. doi:10.5765/jkacap. 190022

19. Heo S, Kim J-H, Joung Y-S, et al. Clinical utility of the Korean version of the WHO adult attention-deficit/hyperactivity disorder self-report scale screener. Psychiatry Investig. 2018;15(3):325. doi:10.30773/pi.2017.07.10

20. Ramos-Quiroga JA, Nasillo V, Richarte V, et al. Criteria and concurrent validity of DIVA 2.0: a semi-structured diagnostic interview for adult ADHD. J Atten Disord. 2016.

21. Pettersson R, Soderstrom S, Nilsson KW. Diagnosing ADHD in adults: an examination of the discriminative validity of neuropsychological tests and diagnostic assessment instruments. J Atten Disord. 2018;22(11):1019-1031. doi:10.1177/1087054715618788
22. Kessler RC, Adler LA, Gruber MJ, Sarawate CA, Spencer T, Van Brunt DL. Validity of the World Health Organization adult ADHD self-report scale (ASRS) screener in a representative sample of health plan members. Int $J$ Methods Psychiatr Res. 2007;16(2):52-65. doi:10.1002/mpr.208

23. Mannuzza S, Klein RG. Long-term prognosis in attention-deficit/ hyperactivity disorder. Child Adolesc Psychiatr Clin. 2000;9 (3):711-726. doi:10.1016/S1056-4993(18)30114-7

24. Halmøy A, Fasmer OB, Gillberg C, Haavik J. Occupational outcome in adult ADHD: impact of symptom profile, comorbid psychiatric problems, and treatment: a cross-sectional study of 414 clinically diagnosed adult ADHD patients. $J$ Atten Disord. 2009;13 (2):175-187. doi:10.1177/1087054708329777

25. Silva D, Colvin L, Glauert R, Stanley F, Srinivas Jois R, Bower C. Literacy and numeracy underachievement in boys and girls with ADHD. J Atten Disord. 2015;1087054715613438.

26. Voigt RG, Katusic SK, Colligan RC, Killian JM, Weaver AL, Barbaresi WJ. Academic achievement in adults with a history of childhood attention-deficit/hyperactivity disorder: a population-based prospective study. J Dev Behav Pediatr. 2017;38 (1):1. doi:10.1097/DBP.0000000000000358

27. Barkley RA, Murphy KR. Impairment in occupational functioning and adult ADHD: the predictive utility of executive function (EF) ratings versus EF tests. Arch Clin Neuropsychol. 2010;25 (3):157-173. doi:10.1093/arclin/acq014

28. Hwangbo R, Chang H, Bahn GH. Diagnostic Distribution of Psychiatric Disorders among Korean Young Adults. J Korean Acad Child Adolesc Psychiatry. 2020;31(2):80-87
Neuropsychiatric Disease and Treatment

\section{Publish your work in this journal}

Neuropsychiatric Disease and Treatment is an international, peerreviewed journal of clinical therapeutics and pharmacology focusing on concise rapid reporting of clinical or pre-clinical studies on a range of neuropsychiatric and neurological disorders. This journal is indexed on PubMed Central, the 'PsycINFO' database and CAS, and

\section{Dovepress}

is the official journal of The International Neuropsychiatric Association (INA). The manuscript management system is completely online and includes a very quick and fair peer-review system, which is all easy to use. Visit http://www.dovepress.com/testimonials.php to read real quotes from published authors. 